\title{
Effect of Motivation on Personnel Performance in the Workplace
}

\author{
Muyiwa Adeniyi Sholarin ${ }^{1}$, Idoko Joseph Onyebuchukwu ${ }^{2}$ \\ ${ }^{1}$ Counselling Centre, Covenant University, Ota, Nigeria \\ ${ }^{2}$ Department of Psychology, School of Human Resource Development, College of Leadership \& Development Studies, Covenant University, \\ Ota, Nigeria
}

\section{Email address:}

joseph.idoko@covenantuniversity.edu.ng (I. J. Onyebuchukwu), josephidoko11@gmail.com (I. J. Onyebuchukwu), el4idj@yahoo.com (I. J. Onyebuchukwu), solarinadeniyi@gmail.com (M. A. Sholarin)

\section{To cite this article:}

Muyiwa Adeniyi Sholarin, Idoko Joseph Onyebuchukwu. Effect of Motivation on Personnel Performance in the Workplace. Journal of Human Resource Management. Vol. 4, No. 5, 2016, pp. 61-64. doi: 10.11648/j.jhrm.20160405.13

Received: July 13, 2016; Accepted: August 25, 2016; Published: October 19, 2016

\begin{abstract}
The study was on the effect of motivation on the personnel performance in the work place. Staffs of Assurance alliance 1.t.d Lagos were used. One hundred staffs were randomly selected, their age is between 20 to 50 years old, 54 were male $(52.9 \%)$ while 46 were female $(45.1 \%), 46$ were junior cadre $(45.1 \%), 41$ were middle level cadre $(40.2 \%)$ and 13 were senior level cadre (12.7\%). Four hypotheses were tested. The result was analyzed using S.P.S.S.. Recommendations were made.
\end{abstract}

Keywords: Motivation, Personnel, Performance and Work Place

\section{Introduction}

Based on the present global economic trend, most employers of labor have realized the fact that for their organizations to compete favorably, the performance of their employees goes a long way in determining the success of the organization. Performance of employees in an organization is vital, not only for the growth of the organization but also for the growth of individual employees [1].

Motivation is the appropriate reward system/package that can jeer up or motivate employees to develop positive attitude towards their job and thereby increase their productivity. Motivation can be either extrinsic or intrinsic [2, 3, 4].

Extrinsic motivation comes from the outside of the individual; it involves reward like money, grade, promotion etc. Most often it involves coercion and threat of punishment. Extrinsic motivation encourages competition because a winner must emerge to take the price; even a crowd cheering an individual and trophies are all extrinsic motivation. Selfdetermination theory proposes that extrinsic motivation can be internalized by an individual an individual if the tasks fits with their values and beliefs and contributes in fulfilling their basic psychological needs.
Intrinsic motivation cannot be manipulated because it comes from the individual. They are those rewards that can be termed psychological. They include receiving appreciation, positive recognition, and being treated in a caring and considerate way $[5,6,7]$

Performance is also a part of human resource management; it is an important criterion for organizational outcomes and success. Job performance is an individual level variable, or something a single person does. Performance is being able to carry out your job requirement effectively and understanding, completing an up to date job description required of the position $[8,9]$.

\subsection{Statement of Problem}

The survival of any organization rests on the performance/quality of work done by the personnel (employee). Many organizations suffer from poor performance because of lack of awareness of the important role motivation plays in personnel performance. Employers tend to forget that motivation applied promptly and appropriately brings out the best in employees their by 
achieving individual and group goals leading to increase in organization's productivity and profitability.

\subsection{Objective of the Study}

To identify solution to the lack of motivation in organizations.

To ascertain that various forms of motivation satisfies personnel individually.

To compare which is more effective between intrinsic and extrinsic motivation.

\subsection{Research Questios}

How are workers motivated?

What are the different forms of motivation and how relevant are they in influencing personnel performance.

\subsection{Relevance/Significance of the Study}

This study is to certify the need for motivation in the work place by pointing out specific areas employers should concentrate on, in motivating their employees.

\subsection{Research Hypotheses}

(1). There will be a significant relationship between motivation and personnel performance.

(2). There will be a significant difference in performance due to age

(3). There will be a significant difference in employee's performance between male and female.

(4). Position has no significant effect on performance.

\section{Method Design}

This study which examined the effect of motivation on personnel performance in the work place adopted survey design. The independent variable is motivation while the dependent variable is personnel performance.

\subsection{Setting}

The study took place in assurance alliance Nigeria limited, Victoria Island, Lagos State. The personnel working here are graduates which comprises junior, middle level and senior cadre.

\subsection{Participants}

The participants were one hundred personnel of capital alliance. Their ages ranges from 20 to 50 years. There were 54 (53.9\%) male and $46(46.1 \%) .20$ to 29 years were $37(36.3 \%)$, 30 to 39 years were $47(46.1 \%)$, and 40 to 50 years were 16 (15.7\%). Junior cadres were 46 (46.1\%), middle level cadres were $41(41.2 \%)$ and senior cadres were $13(12.7 \%)$.

\subsection{Sampling Technique}

The simple random sampling method was used to select the participants because of the nature of the study which entails administering questionnaire to staffs of capital alliance.

\subsection{Instrument}

A structured motivational questionnaire developed by the researcher (cronbach alpha co efficient of 0.70 and internal consistence of 0.82 ) and performance scale developed by Brown and Leigh (1996) was adapted by the researcher to establish its reliability and validity. The questionnaire consists of different sections with each of the sections collecting information on the variable of interest. It comprises sections A, B, and C. It is a likert type scale. The structure of the questionnaire is outlined below.

\section{SECTION A}

In this section of the questionnaire, demographic information of the participants were captured ranging from age, gender and position.

\section{SECTION B}

This instrument measured the motivation of the participants.

\section{SECTION C}

This instrument measured the work place performance of the participants.

\subsection{Procedure for Data Collection}

The researcher randomly selected one hundred personnel of assurance alliance Nig. Limited, Nigeria using simple random selection. The respondents cut across age, sex and position. The criteria for inclusion were; must be an employee of capital alliance and will be above fifty years of age. The respondents were approached, having acquainted them of the researcher's intention. The respondents consent was duly sought by asking them whether they will participate in the study and signing the consent form. Those who responded in the affirmative participated in the study, while also at the same time requesting them to pick one ballot paper from the basket presented to them. Those who picked 'Yes' written on the card were drawn into the study while those that picked 'No' were excluded from the study. This procedure ensured that every participant was given equal opportunity of participating in the study. Prior to given the questionnaires to them to fill, the researcher instructed them on how they were expected to respond to the statements in the questionnaire (i.e., they should tick on a line in each statement and that the questionnaire should be filled completely as half filled questionnaire would be rendered invalid). Additionally, the participants in the main study were informed that their confidentiality was guaranteed and therefore, they should not write their names on the questionnaires. They were also told albeit individually to mention any areas in the questionnaire they did not comprehend. They admitted that the questionnaire was written in unambiguous language and therefore, they could respond to the statements in the questionnaire almost effortlessly on their own.

\subsection{Statistical Analysis}

Data generated in this study was analyzed using Pearson r, 
independent T- test and Anova

\section{Result}

This chapter presents the result of the study.

Table 1. Age distribution of the respondents.

\begin{tabular}{lll}
\hline Variations & Frequency & Percent \\
\hline $20-30$ & 37 & 36.3 \\
$31-40$ & 47 & 47.1 \\
$41-50$ & 16 & 16.7 \\
Total & 100 & 100 \\
\hline
\end{tabular}

From the table above, the age of the respondents were grouped into three, 20-30 were 37 representing 36.3\%, 31-40 were 47 representing $47.1 \%$ and $41-50$ representing were 16 representing $16.7 \%$, totaling 100 participants.

Table 2. Gender distribution of respondents.

\begin{tabular}{lll}
\hline Variation & Frequency & Percent \\
\hline Male & 54 & 53.9 \\
Female & 46 & 47.1 \\
Total & 100 & 100 \\
\hline
\end{tabular}

The gender distribution revealed that there were 54 males representing $53.9 \%$ and 46 female representing $47.1 \%$.

Table 3. Job status of respondents.

\begin{tabular}{lll}
\hline Variations & Frequency & Percent \\
\hline Junior cadre & 46 & 46.1 \\
Middle level cadre & 41 & 40,2 \\
Senior level cadre & 13 & 13.7 \\
Total & 100 & 100 \\
\hline
\end{tabular}

The job status distribution revealed that there were 46 in the junior cadre representing $46.1 \%, 41$ were in the middle class representing $40.2 \%$ and 13 were senior level cadres representing $13.7 \%$.

HYPOTHESIS 1 There will be a significant relationship between motivation and personnel performance.

Table 4. Motivation and personnel performance.

\begin{tabular}{llllll}
\hline & N & mean & Std. deviation & R score & Sig \\
\hline Motivation & 100 & 121.5300 & 8.75763 & 4.94 & $<0.05$ \\
Job performance & 100 & 87.30000 & 6.77413 & & \\
\hline
\end{tabular}

The first hypothesis was confirmed, there is a significant relationship between motivation and personnel performance; $\mathrm{r}=.494, \mathrm{df}=99<0.05$

HYPOTHESIS 2 There will be a significant difference in performance due to age.

Table 5. (ANOVA) Age and Performance.

\begin{tabular}{|c|c|c|c|c|c|}
\hline & Sum of squares & Do & Mean square & $\mathbf{F}$ & Sig. \\
\hline Between groups & 460.895 & 2 & 230.448 & 3.314 & .048 \\
\hline Within groups & 7132.015 & 98 & 73.526 & & \\
\hline Total & 7592.910 & 100 & & & \\
\hline
\end{tabular}

The second hypothesis was confirmed that there is a significant difference in performance as a result of age, $\mathrm{F}(2,8)=3.134$ at 0.05 significant level.

HYPOTHESIS 3 . There will be a significant difference in employee's performance between male and female.

Table 6. (ANOVA) Gender and Performance.

\begin{tabular}{lllllll}
\hline Variations & No & Mean & Std Deviation & df & t-observed & Sig. \\
\hline Male & 54 & 122.1296 & 8.86810 & 98 & 0,74 & $>0.05$ \\
Female & 46 & 120.826 & 8.67001 & & & \\
Total & 100 & & & & & \\
\hline
\end{tabular}

The third hypothesis was rejected, there was no significant difference in performance between male and female, $t$ observed $=0.74$, $\mathrm{df}=98$ and $>0.05$.

HYPOTHESIS 4, Position has no significant effect on performance.

Table 7. (ANOVA) Position and Performance.

\begin{tabular}{llllll}
\hline & Sum of squares & df & Mean square & F & Sig. \\
\hline Between groups & 816.176 & 2 & 408.088 & 5.841 & .004 \\
Within groups & 677.734 & 98 & 69.863 & & \\
Total & 7592.910 & 100 & & & \\
\hline
\end{tabular}

The forth hypothesis was accepted, position has no significant in performance, $\mathrm{F}=5.841$ at 0.05 .

\section{Discussion}

The study investigated the central role of motivation in employees' performance. Over the years, employee's motivation has been variously used as independent variable, dependent variable, a moderating variable, a set of processes, a personal characteristics and a situational influence (Kanfer et al 1977)

The result of hypothesis one shows that there is a positive significant relationship between motivation and performance. Lawler et al (1969) posited that large pay package can increase job attendance, employee productivity, reduced absenteeism, improve employee's commitment, organizational integration, speeds up task completion, enhances the spirit of unity (oneness) and a feeling of job security among employees which is consistent with the present findings. Steer et al (1993) noted that different forms of motivation has an effect on individual differently, some will want increased pay, time off, transfer, promotion, training and self-development.

The result of hypothesis two shows that there is a significant difference in performance as a result of age, this may be as a result of the fact that extra responsibilities in other areas of the lives of older workers and the biological factor which tends to reduce the performance of an individual because of age.

The result of hypothesis three shows that there is no significant difference in performance due to gender.

The result of hypothesis four shows that there is no 
significant difference in performance with respect to position.

\section{Conclusion}

In this study incentives were used to explain varieties of organizational phenomena ranging form relationship between incentives and employee's work performance to differential performance among employees doing the same job on the basis of age, sex and work position. The study also found that there is a positive relationship between incentives and employee's performance. Incentives and motivation are major components of all the theories that predict and explain job performance of employees. An individual performs well on the job partly because they are motivated; they focus on their assigned task putting in their best. Motivation as reflected in incentives, undoubtedly drive to a higher performance on the part of the employee. Quick (1985) succinctly said that "the key to effective job performance is motivation". From the forgoing it was concluded that there is a positive and significant relationship between motivation and personnel's performance. The implication is that the more motivation is offered to an employee, the more effective, efficient and zealous the employee becomes in achieving set goals. It was also concluded that there is a significant difference in employee performance on the job as a result of gender. It was concluded that there is a significant difference in the employee's performance as a result of age. Lastly it was also concluded that there is no significant difference in personnel performance with respect to position.

\section{Recommendations}

The study is based on the influence of motivation on personnel's performance. Based on the result it is important and fundamental that employers should find out the best way to motivate their employees for enhanced performance. In Nigeria both the government and private employers should adhere to this and stop complaining of low productivity and poor attitude to work. This will also reduce corruption to barest minimum level as employees will stop cutting corners or trying to help themselves at detriment of the organization.

The consideration of age should be considered in certain types of work, It should be spelt out the work in which age bracket/group will perform better than the other. E.g. marketing which involves a lot of moving around will be for young ones below 50 years as it is rigorous and demanding, while those that are 50 and above will performexcellently in other type of jobs.

As gender has no effect on performance women should be encouraged to go into areas that we erroneously think is exclusive to menfolk. In Nigeria during President Jonathan's era women were admitted into N.D.A. which before then was an exclusive domain of males as ability is not gender sensitive.

\section{Limitations}

Sourcing/getting research grant is not easy, researchers go hungry as a result of non-availability and paucity of funds.

\section{References}

[1] C. P. Alderfer (1969). "An empirical test of a new theory of human needs", Organizational behavior and human performance, pp 142-175.

[2] J. W. Atkinson, (1964) An introduction to motivation, N. Y. Nostrand.

[3] J. P. Campbell et al (1976). Motivation theory in industrial and organizational psychology in M.D. Dunnete (ed), Hand book of organizational psychology, Chicago; Rand McNally.

[4] Kleinginna et al (1981). A categorized list of emotion definitions, with suggestions for a consensual definition. Motivation and Emotion, 5(4), pp, 345-378.

[5] Steer et al (1991), Motivation and work behavior. New York; McGraw-Hill.

[6] Obamiro J. K (2008). Management principles and strategies, largos: Pumark Nigeria Limited.

[7] Rudolph et al (1989) "the art of motivating employees" Journal of managerial psychology.

[8] Alderfer C. (1972). Existence, Relatedness and growth; Human needs in Organizational setting.

[9] Stoner et al $(1989,2002)$. Management, Engle wood cliffs, N. J. Prentice Hall.

[10] Olajide, A. (2000). Getting the best out of the employees in a developing economy. A Personnel Psychology Guest Lecture Series. Department of Guidance and Counselling, University of Ibadan, Nigeria.

[11] Vroom, V. H. 1964. Work Motivation. New York: John Wiley and Sons. 